\title{
Penyiapan Pondasi dan Lantai Bangunan Utama Pengolahan Sampah di Dukuh Ngipikrejo II, Desa Banjararum, Kabupaten Kulonprogo
}

\author{
Iman Haryanto ${ }^{*}$, Hotma P Sulistyadi ${ }^{2}$, Syaukat Ali ${ }^{3}$, Wiryanta ${ }^{4}$, Edi Kurniadi ${ }^{5}$, \\ Agus Kurniawan ${ }^{6}$ \\ 1,2,3,4,5,6 Departemen Teknik Sipil, Sekolah Vokasi, Universitas Gadjah Mada \\ *Email:imanh@ugm.ac.id
}

\begin{abstract}
Abstrak
Desa Banjararum belum memiliki tempat pengelolaan kompos sampah (TPS). Kegiatan pengabdian masyarakat bertujuan menyusun site plan kawasan TPS, desain teknis bangunan TPS (khususnya pondasi dan lantai), serta melaksanakan pembangunan TPS. Lokasi pembangunan adalah tanah kas desa, seluas kurang lebih $1000 \mathrm{~m}^{2}$. Tahap kegiatan mencakup survei lokasi, pengukuran lahan, penyiapan site plan TPS, review dan finalisasi site plan oleh tim dan pemerintah desa, pembersihan lahan, pemasangan bouwplank, penggalian pondasi, pemasangan pondasi batu kali, urugan tanah dan/atau pasir levelling lantai, pelaksanaan elemen struktur lain (kolom, dinding, atap), pemasangan lantai keramik, dan pelaporan. Data teknis bangunan terdiri dari luasan lantai $11 \times 6 \mathrm{~m}$, kolam pemeraman 3 buah berukuran $3,5 \times 4 \mathrm{~m}$ per kolam, pondasi menerus batu kali (dengan ukuran tinggi, lebar bawah dan lebar atas o,6×0,6×0,3 $\mathrm{m})$, serta lapisan dasar bawah pondasi berupa pasir urug dan batu kosong. Mitra pemerintah desa membantu kegiatan tim, melalui penyiapan tenaga pelaksana, pengadaan material bangunan, dan pengawasan harian.
\end{abstract}

Kata Kunci: tempat pengolahan kompos sampah, site plan, pondasi, lantai.

\begin{abstract}
Banjararum village does not have solid waste processing facility ("tempat pengolahan sampah" atau TPS) yet. The community service activity program aims to design TPS area site plan, TPS building (especially foundation and floor), and carry out the construction work. The building is located at village property site and includes area of $1000 \mathrm{~m}^{2}$. The work activities include location survey, surveying, site plan preparation, review and finalizing of site plan by team and village government partner, land clearing, bouwplank fixing, cut work, foundation construction, soil filling for floor levelling, construction of other building elements (column, wall, roof), tile fixing, and reporting. Technical data are consisted: floor area by dimension of $11 \times 6 \mathrm{~m}$, three maturity pools by dimension $3.5 \times 4 \mathrm{~m}$ per pool, continuous river stone foundation (by dimension of height, base width, and top width of $0,6 \times 0,6 \times 0,3 \mathrm{~m}$ ) and a layer beneath foundation made by river sands and stones. Village government partner assists team work through labor and material procurement and carry out daily supervising.
\end{abstract}

Keywords: solid waste processing facility; site plan; foundation; floor. 


\section{PENDAHULUAN}

Desa Banjararum adalah salah satu desa di Kecamatan Kalibawang, Kabupaten Kulonprogo. Batas-batas desa adalah sebagai berikut.

1. Sebelah utara : Desa Banjarasri dan Desa Banjarharjo Kecamatan Kalibawang.

2. Sebelah timur : Sungai Progo/ Kab. Sleman

3. Sebelah selatan : Desa Pendoworejo Kec.Girimulyo dan Desa Kembang (Kec. Nanggulan).
4. Sebelah barat: Desa Purwosari Kec. Girimulyo dan Desa Purwoharjo, Kec. Samigaluh

Desa Banjararum terdiri dari 26 pedukuhan, 52 RW, dan 104 RT. Data kependudukan desa adalah sebagai berikut. 1. Jumlah KK $\quad: 3.043 \mathrm{KK}$

2. Jumlah Penduduk : 9.209 Jiwa

3. Penduduk Laki-laki $\quad: 4.493$ Jiwa

4. Penduduk Perempuan : 4.716 Jiwa

Tingkat bangkitan sampah padat di Indonesia umumnya mencapai 0,7 $\mathrm{kg} / \mathrm{kapita} / \mathrm{hari}$. Dengan jumlah penduduk Desa Banjararum sebanyak 9.209 jiwa, maka perkiraan jumlah bangkitan sampah padat

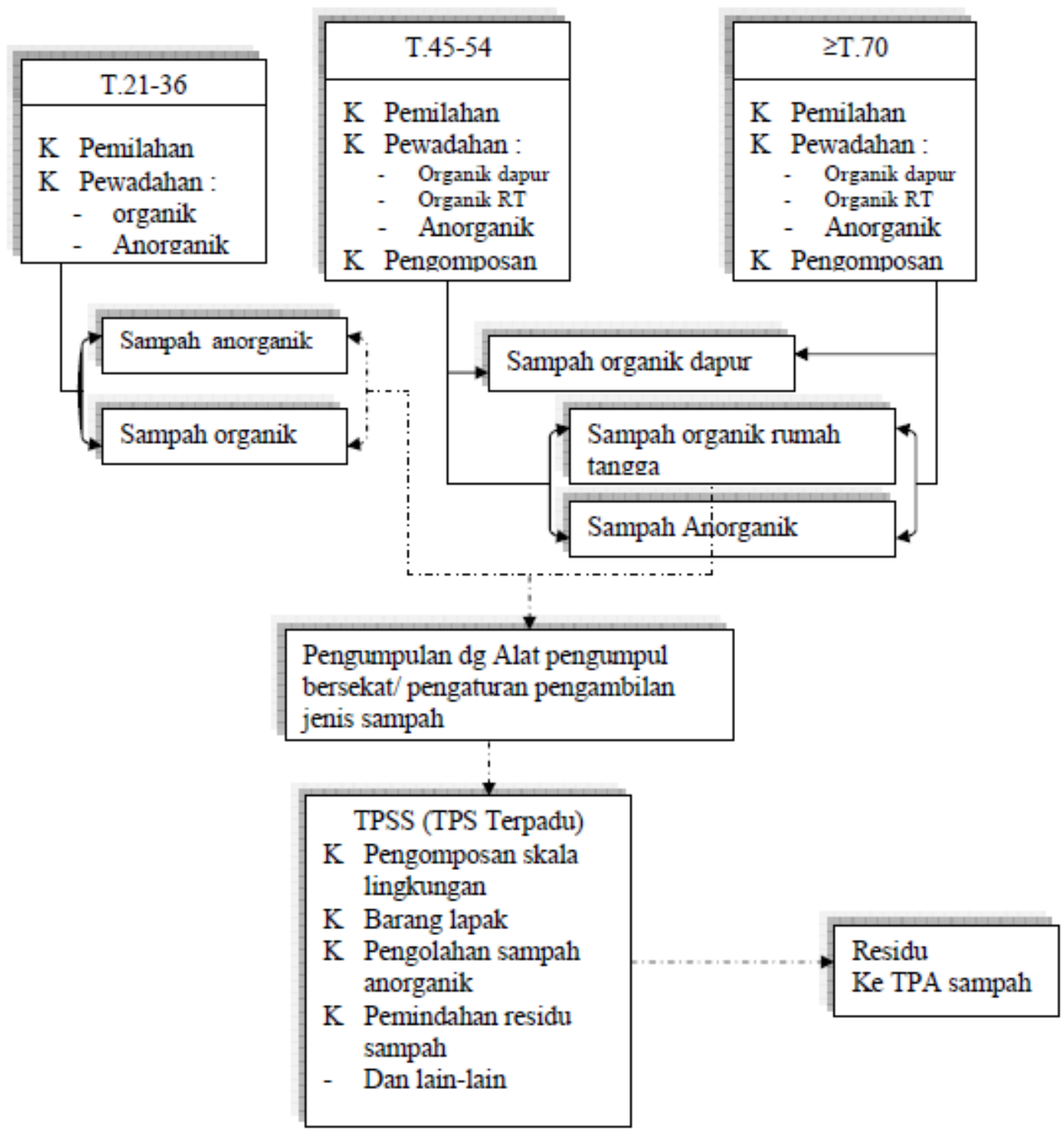

Gambar 1. Diagram alir pengelolaan dan pengolahan sampah domestic 
mencapai $0,7 \mathrm{~kg} / \mathrm{kapita} /$ hari $\times 9.209$ jiwa $=$ $6.446 \mathrm{~kg} / \mathrm{hari}$ atau 6,5 ton. Selama ini, masyarakat menangani timbulan sampah secara sendiri-sendiri. Hal tersebut berpotensi menimbulkan resiko kesehatan dan mengabaikan potensi ekonomi sampah.

Pemerintah Desa Banjararum memiliki rencana pengelolaan sampah (TPS) desa secara terpadu. Pemerintah desa berencana membangun TPS di tanah kas desa. Lokasi rencana TPS berada di Dukuh Ngipikrejo II dengan luasan tidak kurang dari $1000 \mathrm{~m}^{2}$. Permasalahan yang dihadapi adalah belum adanya site plan kawasan TPS dan desain teknis bangunan TPS, serta lokasi TPS yang berada di dekat sungai.

Solusi yang ditawarkan untuk mengatasi masalah terkendalanya pembangunan TPS adalah dengan menyiapkan site plan kawasan TPSdan desain teknis bangunan TPS. Desain teknis TPS mencakup struktur bawah, penyokong dan struktur atas. Secara teknis, bangunan TPS merupakan bagian proses pengelolaan dan pengolahan sampah domestic. Gambar 1 menyajikan diagram alir pengelolaan dan pengolahan sampah domestik.

Kegiatan pengabdian masyarakat ini bertujuan membangun pondasi dan lantai. Struktur pondasi menggunakan pondasi menerus dari pasangan batu kali dengan adukan pasir dan semen. Alternatif lantai menggunakan keramik atau ubin atau plesteran.

\section{METODE}

Metode pelaksanaan kegiatan mencakup tahapan kegiatan sebagai berikut.

1. Survei lokasi.

2. Pengukuran lahan.

3. Penyiapan site plan TPS.

4. Review dan finalisasi site plan oleh tim dan mitra.

5. Pembersihan lahan.

6. Pemasangan bouwplank.

7. Penggalian pondasi.

8. Pemasangan pondasi batu kali.

9. Urugan tanah dan/atau pasir levelling lantai.

10. Pemasangan lantai keramik.

11. Pelaporan.

Perencanaan dan konstruksi bangunan TPS didesain menggunakan metode work breakdown system.

Pemerintah dan masyarakat Desa Banjararum berpartisipasi dalam pelaksanaan program. Bentuk partisipasinya adalah penyediaan lokasi TPS, kerja bakti tenaga, penyediaan material batu kali dan kayu, serta pembiayaan dana talangan untuk tenaga kerja teknis. Gambar 2 dan 3 menyajikan lokasi rencana TPS dan kondisi salah akses ke TPS.

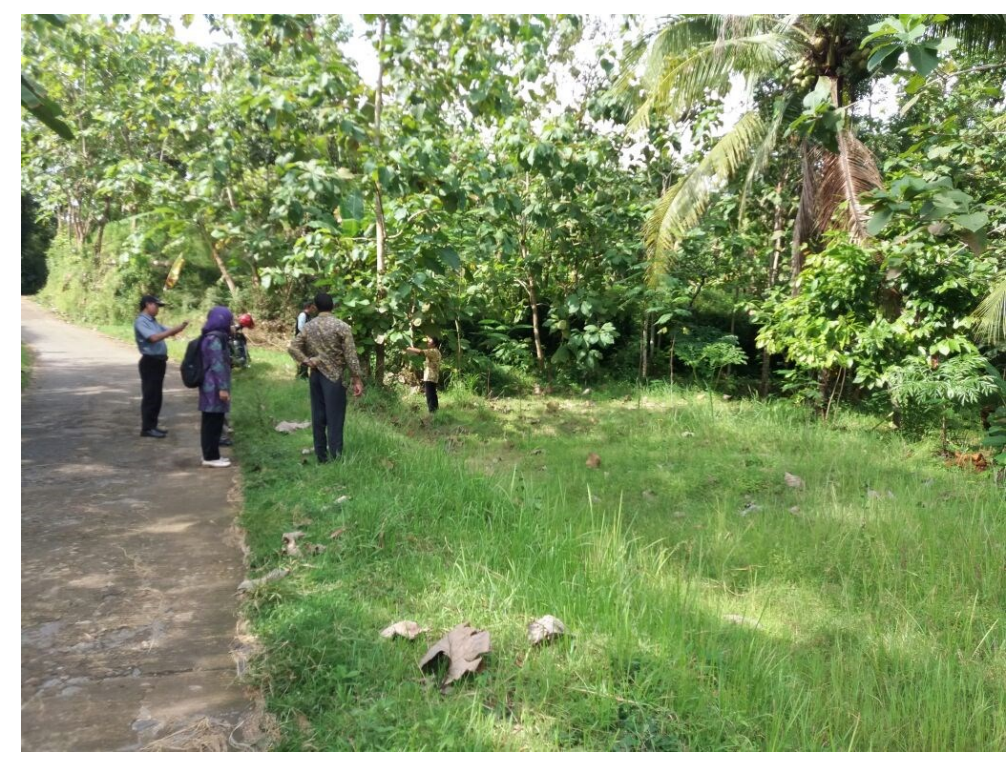

Gambar 2 Lokasi rencana TPS 


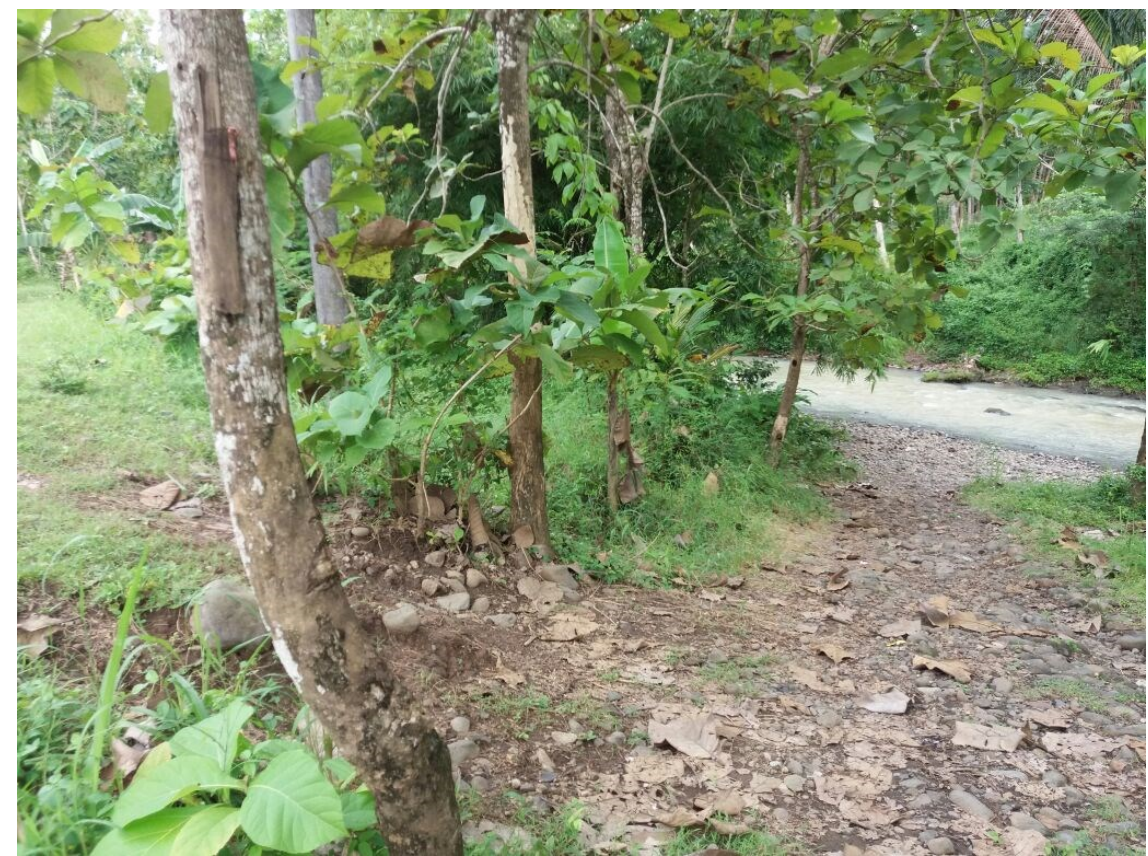

Gambar 3 Kondisi salah satu akses dan sungai di sekitar lokasi rencana TPS

HASIL DAN PEMBAHASAN

Kegiatan pengabdian masyarakat dilaksanakan dengan jadwal sebagai berikut.

Tabel 1 Jadwal kegiatan

\begin{tabular}{|c|c|c|c|c|c|c|c|c|}
\hline \multirow[t]{2}{*}{ No } & \multirow[t]{2}{*}{ Kegiatan } & \multicolumn{7}{|c|}{ Tahun 2017} \\
\hline & & Apr & Mei & Jun & $\mathrm{Jul}$ & Ags & Sep & Okt \\
\hline 1 & $\begin{array}{c}\text { Survei lokasi } \\
\text { dan } \\
\text { penyusunan } \\
\text { proposal }\end{array}$ & & & & & & & \\
\hline 2 & $\begin{array}{c}\text { Pengukuran } \\
\text { lahan }\end{array}$ & & & & & & & \\
\hline 3 & $\begin{array}{c}\text { Penyiapan site } \\
\text { plan TPS }\end{array}$ & & & & & & & \\
\hline 4 & $\begin{array}{c}\text { Pembersihan } \\
\text { lahan }\end{array}$ & & & & & & & \\
\hline 5 & $\begin{array}{l}\text { Pemasangan } \\
\text { bouwplank }\end{array}$ & & & & & & & \\
\hline 6 & $\begin{array}{l}\text { Penggalian } \\
\text { pondasi }\end{array}$ & & & & & & & \\
\hline 7 & $\begin{array}{c}\text { Pemasangan } \\
\text { pondasi batu } \\
\text { kali }\end{array}$ & & & & & & & \\
\hline 8 & $\begin{array}{l}\text { Urugan tanah } \\
\text { dan/atau pasir } \\
\text { levelling lantai }\end{array}$ & & & & & & & \\
\hline 9 & $\begin{array}{c}\text { Plesteran } \\
\text { lantai }\end{array}$ & & & & & & & \\
\hline 10 & Pelaporan & & & & & & & \\
\hline
\end{tabular}


Hasil yang dicapai berupa gambar rencana dan pembangunan fisik. Gambar 4 dan 5 menyajikan denah bangunan dan gambar rencana pondasi. Gambar 6 menyajikan kemajuan pekerjaan fisik pembangunan bangunan pengolah kompos sampah. Data teknis denah dan pondasi bangunan pengolah kompos sampah adalah sebagai berikut.

1. Ukuran bangunan $11 \times 6 \mathrm{~m}$.

2. Jumlah kolam pemeraman 3 buah dengan ukuran per kolam 3,5×4 m.

3. Jumlah kolom praktis 10 dengan ukuran kolom 0,15×0,15 m.
4. Jenis pondasi adalah pondasi menerus batu kali.

5. Tinggi pondasi o,6 $\mathrm{m}$ dengan lebar bawah o,6 $\mathrm{m}$ dan lebar atas o,3 $\mathrm{m}$

6. Lapisan dasar bawah pondasi berupa susunan pasir urug dan batu kosong.

7. Plesteran lantai.

Tabel 2 menyajikan perhitungan anggaran biaya kegiatan fisik pembangunan fondasi dan lantai.

Tabel 2 Perhitungan anggaran biaya kegiatan fisik pembangunan fondasi dan lantai

\begin{tabular}{lcccc}
\hline No & Bahan & Volume & Biaya Satuan (Rp) & Biaya (Rp) \\
\hline 1 & Pembersihan lahan & 1 & 400.000 & 400.000, oo \\
2 & Pemasangan bouwplank & 40 & 50.000 & $2.000 .000,00$ \\
3 & Galian tanah pondasi & 18 & 100.000 & $1.800 .000,00$ \\
4 & Pasang batu kali & 18 & 125.000 & $2.250 .000,00$ \\
5 & Urugan tanah levelling lantai & $7 \cdot 5$ & 55.000 & $412.500,00$ \\
6 & Plesteran lantai & 50 & 62.500 & 3.125 .000$, oo \\
\hline & Jumlah Biaya & & & $9.987 .500,00$
\end{tabular}

Secara umum kegiatan pengabdian masyarakat berlangsung lancar. Pemerintah desa membantu sepenuhnya pelaksanaan tugas tim, terutama dalam bentuk penyiapan

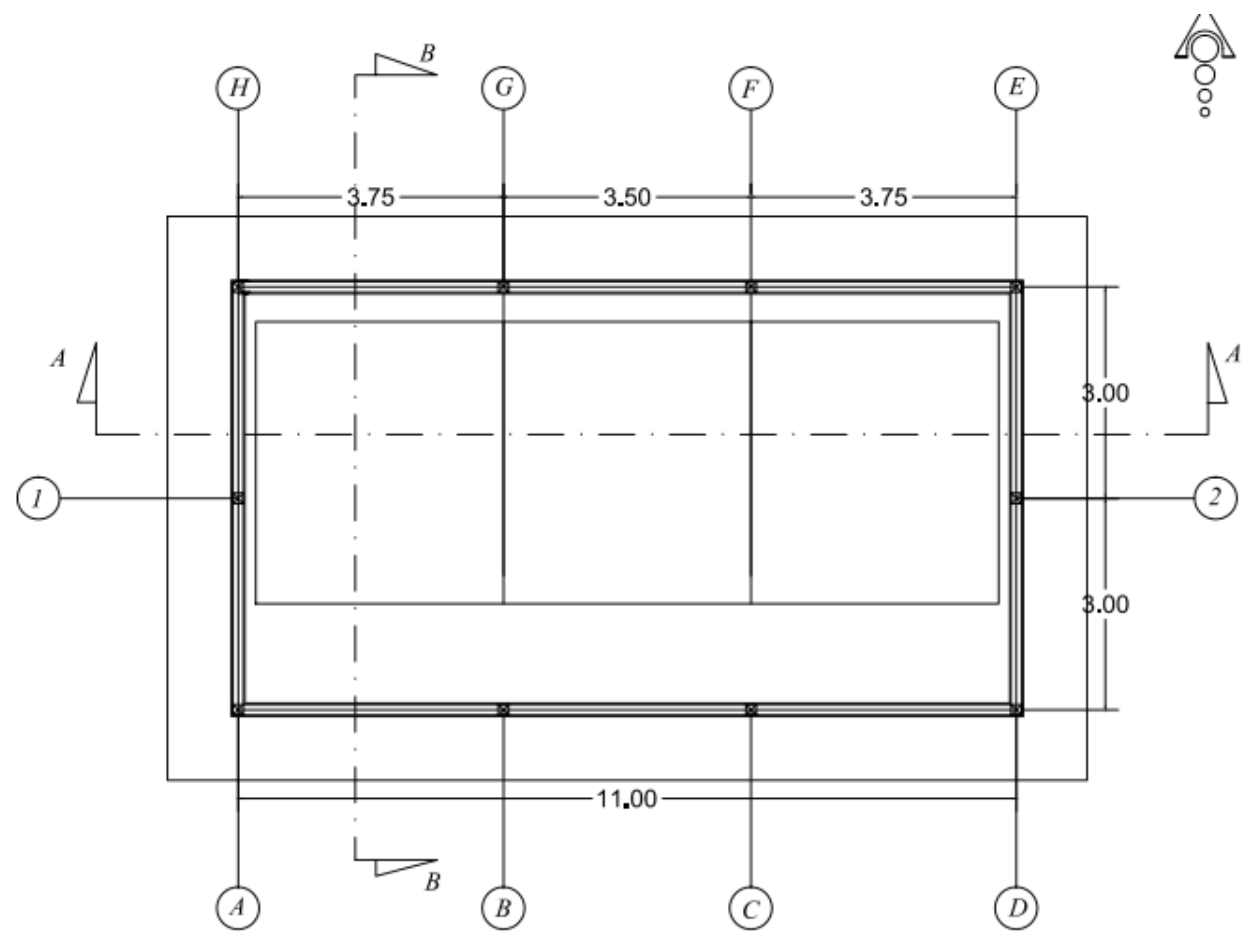

tenaga

Gambar 4 Denah bangunan pengolah kompos sampah 

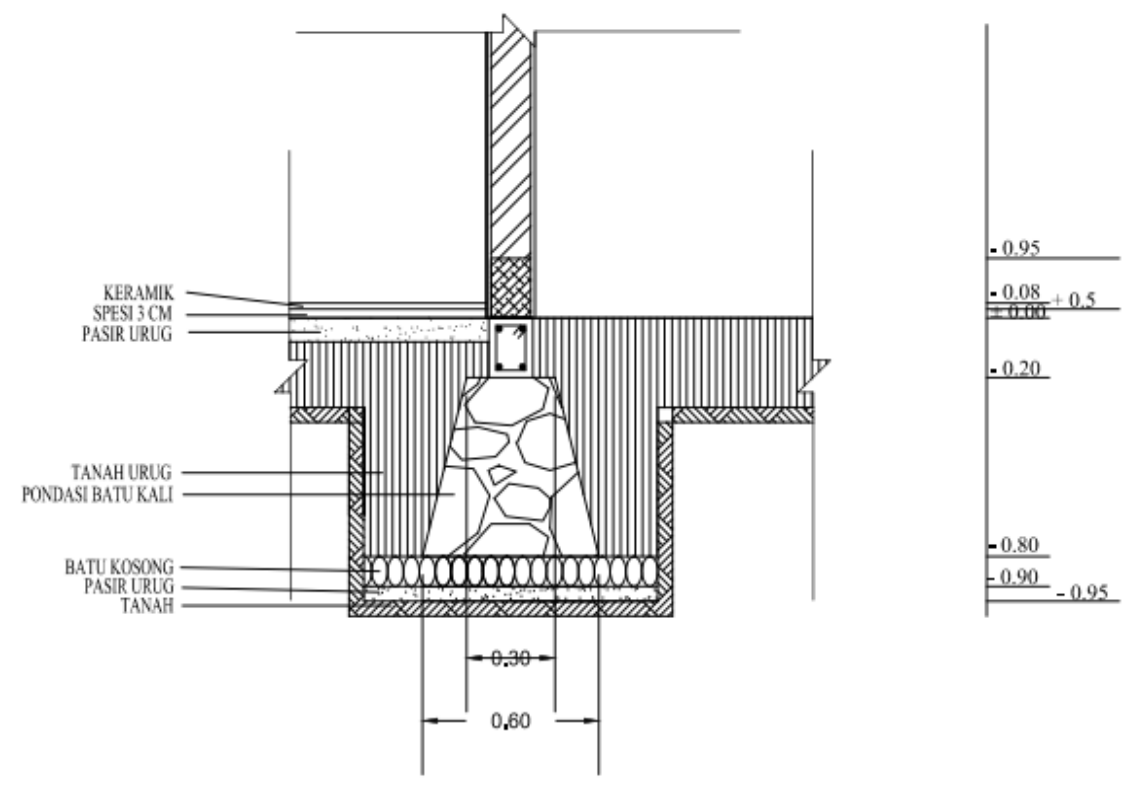

Gambar 5 Gambar rencana pondasi

pelaksana, penyiapan material bangunan, dan pengawasan harian.

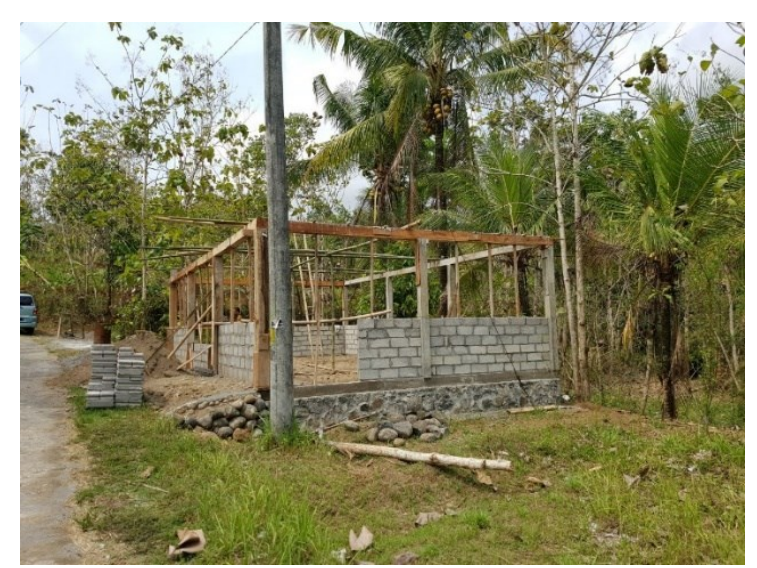

a. Capaian fisik pondasi bangunan

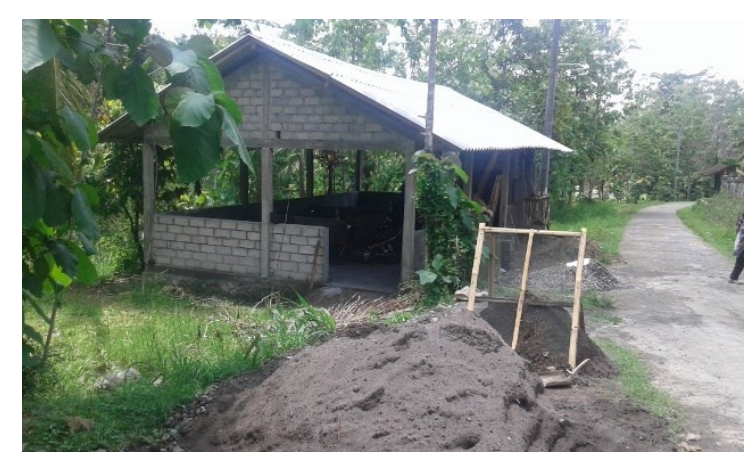

b. Capaian fisik penyelesaian bangunan

Gambar 6 Kemajuan dan penyelesaian pekerjaan fisik pembangunan bangunan pengolah kompos sampah

\section{SIMPULAN}

Simpulan kegiatan pengabdian masyarakat adalah sebagai berikut.

1. Site plan kawasan dan desain teknis bangunan TPS Desa Banjararum sudah disusun

2. Konstruksi bangunan TPS berjalan lancar

3. Struktur pondasi telah selesai dibangun

4. Plesteran lantai telah selesai dilaksanakan.
5. Pemerintah desa membantu sepenuhnya pelaksanaan tugas tim, dalam bentuk penyiapan tenaga pelaksana, pengadaan material bangunan, dan pengawasan harian. 